\title{
Justification of Statutory Service Life Extension of Locomotives on the Basis of Theory of Aging
}

\author{
Oleksandr Krasheninin ${ }^{1}$, Oleksandr Klymenko ${ }^{1}$, Olena Ponomarenko ${ }^{1}$ *, Serhii Yakovlev ${ }^{1}$ \\ ${ }^{1}$ Ukrainian State University of Railway Transport \\ *Corresponding author E-mail: Inpo5005@gmail.com
}

\begin{abstract}
The article is devoted to statutory service life extension of locomotives on the basis of mathematical methods and provisions of the following theories: reliability, games, probability, aging, pattern recognition, and others. Methods of reliability theory have been used to simulate a system of repairs and critical assessment of options for organization of maintenance and repair in excess of statutory service life of locomotives. Methods of game theory are used to determine the tactics of locomotive maintenance over normative term of use. Methods of probability theory and mathematical statistics are used for collecting and processing initial data, the laws of distribution of random variables of working properties and loads are determined in the calculation of the reliability of bearing structures of locomotives, as well as the effectiveness of replacing the old rolling stock with a new one. Methods based on the theory of aging to determine values of criteria for estimating boundary terms for various variants of the strategy of prolonging the operation of locomotives in excess of the normative term. Methods of pattern recognition theory are used to adjust the system of obtaining locomotives in excess of the normative lifetime.
\end{abstract}

Keywords: Maintenance; Non-routine Maintenance; Statutory Service Life Extension; Theory of Reliability; Theory of Aging.

\section{Introduction}

Increasing the efficiency of locomotive use in modern conditions is one of the prerequisites for the stable functioning of railways. There is a search for stocks in determining the limitation period for the use of locomotives. As experience of rolling stock in common industries shows, in some cases it is possible to obtain significant economic effect.

As was emphasized in the management documents of Ukrzaliznytsya that significant part of locomotives has expired the normative life. The age of the exploited fleet of locomotives has reached critical limit. The demolition of electric locomotives has reached $90 \%$ with an average age of locomotive of 36 years.

Due to the physical and moral depreciation of the rolling stock, in particular locomotive park, an important direction in ensuring operation of rail transport in the long run is the rational use of existing rolling stock within normative and extended (over normative) terms of service. Therefore, during the last years, according to the tasks of the State Administration of Railway Transport of Ukraine (Ukrzaliznytsya), scientific and technical developments are being intensively carried out to increase the service life of locomotives without worsening of traffic safety and reliability indicators.

Numerous studies in our country and abroad are devoted to the problems of increasing efficiency of locomotives. Priority in these studies was devoted to determining the optimal structure of repair cycles, the introduction of diagnostic tools in the technological processes of maintenance and repair and evaluation of technical condition before and after repair. Recently attention has been paid to the development of scientific measures to evaluate the effectiveness of lengthening life of locomotives after normative term of its operation. Unfortunately, in the railway transport of
Ukraine, unified scientific direction concerning optimal life cycle of railway traction rolling stock is not substantiated. As the analysis shows, in different countries and organizations due to various economic and political situations, different concepts of life cycle are interpreted differently. One of the important measures is scientific justification of life of the bearing structures of the locomotives and practical measures to ensure fault-free and safe operation of them.

However, it should be noted that these should not outline approaches to the effective operation of locomotives in aftermath of statutory operating period.

Relevance is recorded depending on what you do, at the optimal cost of Maintanance and Repair, scientific examination in accordance with conditions and norms.

\section{Literature Review}

Determination of optimal service life of machines is directly related to the problems of wear aging of machines [16].

A number of authors believe that the optimal lifetime of machines is such that the total cost of repairs of the machine is approaching cost of the new machine $[1,15]$.

This approach can not be considered strictly scientific because in this case it is not analyzed the question of how effectively the means used to purchase and maintain the performance of the old machine.

More substantiated approaches to this issue are given in $[6,7,18]$, where it is assumed that the depreciable service life, for example, of a vehicle, is conditionally determined by the life of the frame or the body of the carrier. However, these statements are not supplemented by analytical evidence. 
The contradiction in the decision of the problem of determining the optimal terms of the service of machines and equipment is stated in [6], which shows that the service life of the machine is determined ultimately by the profitability or disadvantage of their further exploitation and the possibility of replacement by new types of machines of advanced design.

In work [18] it is suggested to consider three criteria for the evaluation of the technical state of the machine parts or their combinations and nodes: technical, technological and economic.

An essential disadvantage of research $[19,20]$ is that they lack universality. Modern machines are quite complicated and it is not known how to determine these characteristics in a certain ratio to find the optimal service life in general.

Most foreign authors [3-5, 21], on the basis of practical materials, set average terms of operation of machines within the limits of 15 to 20 years.

The task of constructing an optimal system of repair using cost information was solved by R.N. Kolehaiev [9]. In the considered model, the vehicle (machine) during the service life goes through a number of planned repairs, according to which the optimal service life "T" and the optimal periods between capital repairs, the number of which can be any $[9,10]$.

In research article [11] it is considered problem within the framework of a stochastic model, which introduces probabilities of machine transitions from one state to another as functions of its age and other factors. In general, the developed model has certain interest, however, with the increase in the number of elements forming the machine, the solution to the problem is complicated.

The research article [2] is solved the task of determining such volumes of repairs, their frequency and service life of the system, in which the required probability of failure-free operation is ensured with a minimal total cost of the means. In doing so, the following assumptions are made that the time for repair and prevention, ignoring the small; in the event of system failure during period of work, a penalty for the refusal is charged; refusals occur with a constant in time intensity.

The diversity of the studies examined shows that there is no single approach to the definition of a strategy beyond the normative exploitation of locomotives $[8,14,22]$.

\section{Materials and Methods}

It is necessary to determine the justification of an effective system of maintenance of locomotives with lengthening of their exploitation period $[12,13,16]$. The research objective is to determine such an option, which corresponds to the minimum cost of maintenance. In this case, the efficiency indicator is the sum of the costs of maintenance (TO), repair (PR) and capital repair (KR), taking into account the cost of energy during the period when it reaches the total output.

Accepted the following values of run-time after the VR $\left(L_{\mathrm{VR}}\right)$ before the write-off, having graduations $L_{\mathrm{VR}}=360,420,450$, and 500 thousand $\mathrm{km}$. The number of PR-3 before write-off should be $1 \div 2$; the number of PR-2 in the period up to PR-3 - $0 \div 1$; the work between the current repairs of the PR-2 and the PR-3 should be reduced with the increase of their serial numbers in the repair cycle before the write-off (ie, instead of the traditional principle of equality and multiplicity of normative developments, the principle of their "differentiation" should be used), since the technical condition of the locomotive tends to deterioration with the growth of its development; standard mileage between TO-3 and PR-1 also need to be reduced with the growth of the time of the locomotive from the VR.

In Table 1, there are eight variants of periodicity and alternations of PR-2 and PR-3 for the adopted four variants of LRP $=360,420$, 450,500 thousand $\mathrm{km}$.
Table 1: Overhaul runs for different repair arrangements

Table 1: Overhaul runs for different repair arrangements
\begin{tabular}{|c|c|c|c|c|c|c|}
\hline $\begin{array}{l}\text { Type of } \\
\text { maintenance } \\
\text { variant }\end{array}$ & $\begin{array}{l}\text { PR - } \\
3(\mathrm{I})\end{array}$ & $\begin{array}{l}\text { PR - } \\
3(\mathrm{II})\end{array}$ & $\begin{array}{c}\text { PR - } \\
2(\mathrm{I})\end{array}$ & $\begin{array}{c}\text { PR - } \\
2(\mathrm{II})\end{array}$ & $\begin{array}{c}\text { PR - } \\
2(\mathrm{III})\end{array}$ & $\begin{array}{c}\sum \mathrm{L}, \\
10^{3} \mathrm{~km}\end{array}$ \\
\hline 1 & 180 & & 100 & 100 & & 360 \\
\hline 2 & 150 & 110 & 80 & 60 & 55 & 360 \\
\hline 3 & 150 & 140 & 80 & & & 360 \\
\hline 4 & 170 & 140 & 90 & 80 & 60 & 420 \\
\hline 5 & 170 & 170 & & 90 & & 420 \\
\hline 6 & 170 & 150 & 90 & 80 & 70 & 450 \\
\hline 7 & 180 & 170 & 100 & 90 & & 450 \\
\hline 8 & 210 & 180 & 120 & 100 & 60 & 500 \\
\hline
\end{tabular}

Features of the options: II - with the usual alternation of repairs, that is, with two PR-3 and three PR-2; III - with two PR-3, but in the period from the LBP to the first PR-3 absent PR-2; I - with one PR-3 and two PR-2 for the run from VR to write-off. Options with $L_{\mathrm{VR}}>360$ ths. $\mathrm{km}$ provide for two repairs of PR-3 and $2 \sigma 3$ repairs of PR-2. The largest mileage to the PR-3 in variants corresponds to the period from VR to I PR-3 (with $L_{\mathrm{VR}}=500$ thousand $\mathrm{km}$ ) and makes 210 thousand $\mathrm{km}$, and the smallest - 110 thousand $\mathrm{km}$ (from I PR-3 to II PR -3 at $L_{\mathrm{VR}}-360$ thousand km).

For each of the eight variants, two types of periodicity of the PR-1 were used in the studies: A - for the period of the diesel locomotive from VR to I, PR-3 - 40 thousand $\mathrm{km}$, for the period from I PR-3 to II PR-3 - 35 thousand. km, from II PR-3 to the end of operation - 30 thousand $\mathrm{km}$; B - respectively, for the specified periods of 35,30 and 25 thousand $\mathrm{km}$. Thus, frequency of PR-1 is also adopted by a differentiated-decreasing period from period to period.

Whereas each of the eight periodic variants has two PR-1 periodic cushions (A and B), 16 repair cycles are subject to review. For each of them, in turn, three varieties of periodicity M-3 are considered: $\mathrm{a}$ - in the period from BP to I PR-3 - 40 days, from I PR-3 to II PR-3 - 30 days, from II PR-3 to end of operation - 25 days; $\mathrm{b}$ - for the specified periods periodicity TO-3 is respectively 35,25 and 20 days; in - 30, 25 and 20 days.

During operation, the suitability of the locomotive, as well as its individual elements, is reduced due to wear during operation, transportation and storage. The suitability of locomotive is partially restored periodically by the use of new equipment or the restoration of some parameters of old equipment. This occurs in the general case as many times as the construction provided by the change of non-durable equipment of the locomotive is carried out, as well as the restoration of parameters of repairable units for maintenance and repair.

Locomotives belong to the category of vehicles (category IV), which consist of unalterable structural elements of initial suitability, as a result of which, in addition to periodic repairs, maintenance is expected.

In general, the initial suitability of a locomotive is equal

$E_{\mathrm{MIV}}=\sum E_{i \mathrm{IV}}+\sum G_{j \mathrm{IV}}=\sum E_{i \mathrm{VV}}+\sum G_{\mathrm{IIV}}+G_{2 \mathrm{IV}}+G_{3 \mathrm{IV}}^{0}$

where $E_{I V}$ is the suitability of all structural elements, $\sum G_{1 \mathrm{IV}}$ is the suitability that corresponds to the long-term active assembly and fitting of structural elements, $\sum G_{2 \mathrm{IV}}$ is the part of suitability of locomotive, which corresponds to a lack of long-acting processing and installation of structural elements, which must be fully restored in terms of repair times during the life of the locomotive, $\sum G_{3 \mathrm{IV}}^{0}$ is the part of suitability of non-constructive elements of the locomotive, which corresponds to the short-acting lubrication and regulation, which, should be periodically restored in use due to partial maintenance of the service life of locomotives.

In the analysis depending on structural components of fitness locomotives and their changes over the lifetime considered that the structure of eligibility locomotive in the opposite during operation is somewhat reduced value life structural elements and simultaneously decreasing suitability long-acting non-constructive 
elements, then renewed the repair of non-constructive elements and, finally, reconditioned in maintenance of non-structural elements, in which consistently introduced a number of renewable usability: $G_{3 \mathrm{IV}}^{0}, g_{3 \mathrm{IV}}^{1}, g_{3 \mathrm{IV}}^{2}, g_{3 \mathrm{IV}}^{3}, \ldots, g_{3 \mathrm{IV}}^{l}, \ldots, g_{3 \mathrm{IV}}^{m_{j}-1}$.

In determining the appropriate values used to construct graphs, part of suitability $g_{2 \mathrm{IV}}^{L}$ has periodicity of change $\tau_{2 \mathrm{IV}}^{L}$, part $g_{3 \mathrm{IV}}^{l}$ periodicity $\tau_{3 \mathrm{IV}}^{l}$, and in the repair of locomotive, since these periodicities are taken multiple, they are introduced simultaneously as components that complement each other.

Following coefficients are used to quantify the suitability.

The coefficient of uniformity is determined by the ratio of the total value of the suitability of the original constructive elements of the locomotive to the total suitability of all structural elements that wear out during the service life

$$
K_{p}=\frac{\sum E_{i}}{\sum n_{i} E_{i}},
$$

where $n_{i}$ is the total number of corresponding structural elements that wear out in the locomotive during its operation.

Practically with sufficient accuracy, coefficient of steadiness is determined from the correlation of corresponding values, that is

$$
K_{\text {stead }}=\frac{\sum E_{i}}{\sum n_{i} E_{i}} \approx \frac{\sum Q_{i}}{\sum n_{i} Q_{i}},
$$

where $Q_{i}$ is the cost of corresponding constructive element.

Coefficient of stability $K_{s}$ of locomotive regulation characterizes the required volumes of work during maintenance and repair and their repetition for the period of operation. Coefficient $K_{s}$ is determined by the ratio of the initial suitability of non-structural elements necessary for the normal operation of the locomotive during its full service life.

$$
K_{s}=\frac{\sum G_{j}}{\sum n_{j} G_{j}} .
$$

In practice, stability coefficient of locomotive regulation is determined with sufficient accuracy due to the corresponding cost indicators, i.e.

$$
K_{s}=\frac{\sum Q_{j}}{\sum n_{j} Q_{j}} \cdot
$$

In case of inequality of the initial and renewable suitability of nonstructural elements $\left(g_{j} \neq G_{j}\right)$ coefficient $K_{\mathrm{c}}$ is determined from the expression

$$
K_{\mathrm{c}}=\frac{\sum G_{j}}{\sum G_{j}+\sum\left(n_{j}-1\right) g_{j}} \approx \frac{\sum Q_{j}}{\sum Q_{j}+\sum\left(n_{j}-1\right) q_{j}},
$$

where $G_{j}$ and $Q_{j}$ is the suitability and cost of output and renewables with adequate maintenance and repair of the structural elements of the locomotive, $n_{j}-1$ is the the number of relevant maintenance and repairs of the locomotive for the entire service life, $g_{j}$ i $q_{j}$ is the respectively, suitability and cost, entered in the locomotive when updating the corresponding non-constructive element.
For a certain non-constructive element of locomotive it is also possible to determine a partial stability factor with respect to the suitability or cost, taking into account the repetition of the renewal of the suitability of this non-constructive element

$$
k_{\mathrm{s} j}=\frac{G_{j}}{G_{j}+\left(n_{j}-1\right) g_{j}}=\frac{Q_{j}}{Q_{j}+\left(n_{j}-1\right) q_{j}} .
$$

The durability coefficient can be determined by expression

$$
K_{\mathrm{d}}=\frac{K_{r} K s E_{M}}{K s \sum E_{i}+K_{r} \sum G_{j}},
$$

or, using value ratios, according to the formula

$$
K_{\mathrm{d}}=\frac{K_{r} K s Q_{u}}{K_{c} \sum Q_{i}+K_{r} \sum Q_{j}}
$$

where $E_{M}$ i $Q_{M}$ is the accordingly the suitability and cost of the locomotive, $E_{i}$ i $Q_{i}$ is the suitability and cost of constructive elements of a locomotive, $G_{j}$ i $Q_{j}$ is the suitability and cost of non-constructive elements of locomotive.

The specific suitability of a locomotive is determined by expression

$\Pi_{n}=\frac{E_{\mu}+\sum\left(n_{i}-1\right) E_{i}+\sum\left(n_{i}-1\right) G_{i}}{T}$,

where $\mathrm{T}$ is the lifetime of locomotive in excess of the normative term.

From the analysis of the structure of the change of suitability of the locomotive during its period of operation, it is possible to make significant adjustments to the existing valuation characteristics.

\section{Results and Discussion}

For 8 variants of lengthening the life of the locomotives after the last KP, the total costs for all types of maintenance, TO, PR and possible unscheduled repairs (HP) were calculated. The amount of TO, PR was calculated according to the accepted variants and is given in Table 2. The costs for TO-3, PR-1, PR-2, PR-3 were taken by the average on the railways and are also shown in Table 2. As practice shows, with As the runway increases, the component of overtime work on TO, PR is increasing. In calculations according to the option of lengthening the life of this component, this component varied in the range of $0.26 \div 0.33$ of the total costs of TO, PR. Accordingly, the mandatory volume of regulatory work in these conditions decreased in opposite to the normative term.

Total costs incurred in unscheduled repairs were taken at $25 \%$ more than over regulatory costs for planned maintenance, maintenance and repair. The factor for increasing the lifetime was taken into account with an increase in the volume of repairs in the range of $1.0 \div 1.25$. Residual price of the locomotive at the start of operation after the $\mathrm{CD}$ was adopted in the amount of $\mathrm{SL}=5 \cdot 106$ $\mathrm{UAH}$.

On the basis of the above calculations carried out, summarized in Table $2, K_{\text {stead }}$ coefficient of steadiness due to planned TO, PR was stable in the range of $0.76 \div 0.73$. Moreover, its least value was the 7th version of the organization of maintenance, PR in after the normative term of exploitation. This testifies that, in compliance 
with the technology of TO, PR is achieving a stable level of equipment maintenance.

\begin{tabular}{|c|c|c|c|c|c|c|c|c|c|c|c|c|c|c|}
\hline \multirow{2}{*}{ 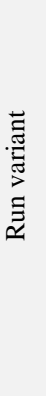 } & \multicolumn{4}{|c|}{ Amount / total cost TO,PR $\left(K_{i} / \sum K_{i} C_{i}\right)$} & \multirow{2}{*}{ 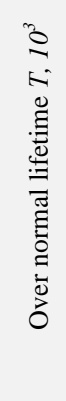 } & \multirow{2}{*}{ 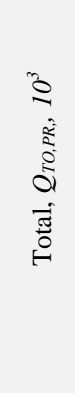 } & \multirow{2}{*}{ 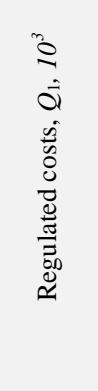 } & \multirow{2}{*}{ 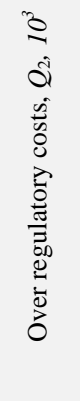 } & \multirow{2}{*}{ 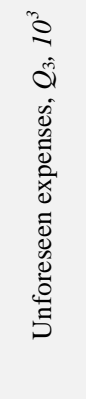 } & \multirow{2}{*}{ 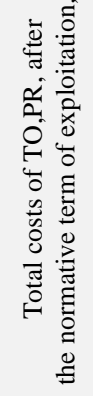 } & \multirow{2}{*}{ 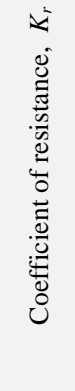 } & \multirow{2}{*}{ 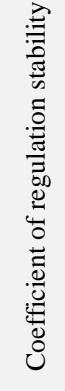 } & \multirow{2}{*}{ 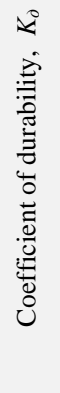 } & \multirow{2}{*}{ 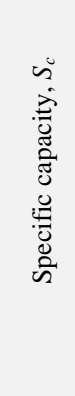 } \\
\hline & 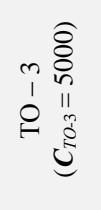 & 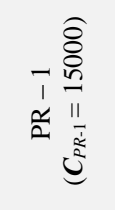 & 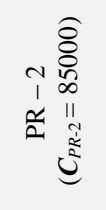 & 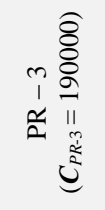 & & & & & & & & & & \\
\hline 1 & $\frac{46}{230000}$ & $\frac{9}{1350000}$ & $\frac{2}{170000}$ & $\frac{1}{190000}$ & 360 & 1940 & 1429.1 & 510.9 & 459.8 & 2399.8 & 0.76 & 0.53 & 0.73 & 19.28 \\
\hline 2 & $\frac{51}{255000}$ & $\frac{8}{1200000}$ & $\frac{3}{255000}$ & $\frac{2}{380000}$ & 360 & 2090 & 1518.7 & 571.3 & 542.7 & 2632.7 & 0.74 & 0.51 & 0.71 & 19.69 \\
\hline 3 & $\frac{47}{235000}$ & $\frac{10}{1500000}$ & $\frac{1}{85000}$ & $\frac{2}{380000}$ & 360 & 2200 & 1576.7 & 623.3 & 623.3 & 2823.3 & 0.74 & 0.50 & 0.69 & 20.00 \\
\hline 4 & $\frac{49}{245000}$ & $\frac{8}{1200000}$ & $\frac{3}{255000}$ & $\frac{2}{380000}$ & 420 & 2080 & 1469.9 & 610.1 & 640.6 & 2720.6 & 0.75 & 0.49 & 0.70 & 16.86 \\
\hline 5 & $\frac{45}{225000}$ & $\frac{10}{1500000}$ & $\frac{1}{85000}$ & $\frac{2}{380000}$ & 420 & 2190 & 1525.7 & 664.3 & 730.7 & 2920.7 & 0.74 & 0.48 & 0.69 & 17.12 \\
\hline 6 & $\frac{50}{250000}$ & $\frac{9}{1350000}$ & $\frac{3}{255000}$ & $\frac{2}{380000}$ & 450 & 2235 & 1534.7 & 700.3 & 805.4 & 3040.4 & 0.74 & 0.47 & 0.68 & 16.08 \\
\hline 8 & $\frac{49}{245000}$ & $\frac{9}{1350000}$ & $\frac{3}{255000}$ & $\frac{2}{380000}$ & 500 & 2230 & 1486.7 & 743.3 & 929.2 & 3159.2 & 0.74 & 0.44 & 0.67 & 14.46 \\
\hline
\end{tabular}

However, when normative term of using locomotives is exceeded, the coefficient of stability of the regulated works $K_{\mathrm{c}}$ with the increase of the life of the operation decreases. The range of changes in $K_{\mathrm{c}} \mathrm{s}$ is observed within the range of $0.55 \div 0.44$. This confirms that when wearing out and aging the equipment is increasingly difficult to maintain the technical condition of the locomotives, especially when there are no special works related to lengthening of service life.

Such nature of change of coefficients $K_{\mathrm{r}}$ and $K_{\mathrm{s}}$ has formed the dynamics of the change in the coefficient of durability $K_{\mathrm{d}}$. Fluctuation range $K_{\mathrm{d}}$ is in range of $0.73 \div 0.67$, which is largely due to the coefficient $K_{\mathrm{r}}$.

The processes of aging of locomotives in excess of the normative term of operation affect the coefficient of specific suitability $S_{c}$. With an increase in lifetime $S_{c}$ is gradually decreases with the growth of total costs in support of the technical condition of locomotives. From this it can be stated that only due to correction of inter-repair runs can not stably maintain the technical condition of locomotives, even with the increase in the cost of scheduled maintenance, PR, which are required by the regulations. As follows from the practice of locomotive operation, it is necessary to adjust the scope of work with each of the following TO, PR due to additional diagnostic testing of equipment, which should be exploited further.

\section{Conclusion}

1. Existing approaches and models of rolling stock maintenance in Ukraine are based on the criteria based on minimization of specific costs per life cycle, which does not fully take into account the peculiarities of the operation of locomotives that continue to use in excess of the normative term.

2. In order to ensure the effective use of locomotives in any period of its operation, the technical operation system should ensure its adaptability to the production sectors in order to optimize the repair base and technology of TO, PR of locomotives.

3. Formed models allow us to determine the suitability of locomotive equipment and its corresponding estimation, which in turn allows us to further adjust the technology TO, PR with allowance for the limiting period of their use in the repair cycle.

\section{Acknowledgement}

The research was carried out within the framework of state budget themes of research work of the Department of Operation and Repair of Rolling Stock of Ukrainian State University of Railway Transport (UkrSURT) in accordance with the provisions of the Program for the extension of the service life of the traction rolling stock (TRS) adopted by the State Administration of Rail Transport of Ukraine and reflected in Order of Ukrzaliznytsia as of June 30, 2010 №093-Ц3 "Regulations on the plan-warning system for the repair of traction rolling stock (electric locomotives, diesel locomotives, electric and diesel trains)" and the terms "State Program of Reforming rail transport in 2010 - 2019" (approved by CMU 16.12.2000 №1390 as amended on 26.10.2011 №1106); "Integrated program of renovation of the railway rolling stock of Ukraine for 2008 - 2020" (approved by the order of Ministry of Infrastructure dated October 14, 2008 No. 1259). 


\section{References}

[1] Avdonkin FN, Teoreticheskiye osnovy tekhnicheskoy ekspluatatsii, Transport, (1985), pp. 115-128, (in Russian).

[2] Barzilovich IT, Kashtanov WA, Nekotoryye matematicheskiye voprosy teorii obsluzhivaniya slozhnykh system, Soviet radio, (1971), pp. 365-373, (in Russian)

[3] Beykhelt F, Franken P, Nadezhnost' i tekhnicheskoye obsluzhivaniye. Matematicheskiy podkhod, Radio i sviaz, (1988), pp. 182-215, (in Russian).

[4] Cox D, Smith V, Teoriya restavratsii, (1967), World, pp. 100-115, (in Russian).

[5] Frerk GV, "System of maintenance of the rolling stock of the State railroads of Germany", Journal Railroads of the world, 5 feb, (1981), pp. 2-8.

[6] Halfying MA, Opredeleniye mezhremontnykh srokov sluzhby mash in v sel'skom khozyaystve, Kolos, (1969), pp. 139-145, (in Russian).

[7] Hazov BF, "Nadezhnost' stroitel'nykh i dorozhnykh mashin", Mechanical engineering, (1979), pp. 111-145 (in Russian)

[8] Bulatov AA, Andronchev IK, Zheleznov DV, Tyapukhin AP, "Combined approach to an assessment of maintenance of electrical equipment on traction rolling stock", Russian Electrical Engineering, Vol. 88, (2017), pp 140-145.

[9] Kolegayev RN, Opredeleniye naiboleye vygodnogo sroka sluzhby avtomobiley, Ekonomizdat, (1963), pp. 127-140 (in Russian)

[10] Kolegayev, RN, Opredeleniye optimal'noy dolgovechnost tekhnicheskikh system, Soviet Radio, (1967), pp. 111-112, (in Russian).

[11] Kolegayev RN, Ekonomicheskaya otsenka kachestva i optimizatsii sistemy remonta avtomobiley, Mechanical engineering, (1980), pp. 138-150, (in Russian)

[12] Krasheninin OS, Obozny OM, Vyznachennya hranychnykh terminiv dovhovichnosti tyahovoho rukhomoho skladu, Coll. of sciences works of Ukr. state acad. of railway trans., Vol. 122, (2011), pp. 134-140, (in Ukrainian).

[13] Krasheninin O.S., Obozny O.M. (2011) Vyznachennya pereodychnosti diahnostuvannya tyahovoho rukho-moho skladu v pislyanormatyvnyy termin ekspluatatsiyi, Coll. of sciences works of Ukr. state acad. of railway trans., Vol. 127, (2011), pp. 118-122, (in Ukrainian).

[14] New technology center for temple mills train service Eurostar, Journal Railway Gazette International, 6 Sep, (2008), pp. 820-821.

[15] Petukhov RM, Metodika ekonomicheskoy otsenki iznosa i sroka sluzhby avtomobiley, Economy, (1965), pp. 167-168, (in Russian)

[16] Tartakovsky ED, Grishchenko SG, Kalabukhin YE, Metody otsenk zhiznennogo tsikla tyagovogo podvizhnogo sostava zheleznykh dorog, Knowledge", pp. 174-175, (in Russian).

[18] Ukharsky VB, Obsluzhivaniye $i$ remont avtobusov. Upravleniye kachestvom i effektivnost, Transport, (1986), pp. 107-121, (in Russian)

[19] Zadeh LA, "Fuzzy sets", Information and control, Vol. 8, No. 3, (1965), pp.338-353.

[20] Zadeh LA, "Outline of a new approach to the analysis of complex systems and decision processes", IEEE Trans. Systems, Man and Cybernetics, Vol.3, (1977), pp. 28-44.

[21] Datsun Y, "Determination of the degree of influence of repair processes on serviceability of units of the traction rolling stock", Eastern-European Journal of Enterprise Technologies, Vol.1, No. 7(79), (2016), pp.56-61.

[22] Zakharov NS, Ziganshin RA, Nekrasov VI, Ziganshina AV, Vasilyev VI. "Method of planning the needs in spare parts when operating special vehicles", International Journal of Pure and Applied Mathematics, Vol. 118, (2018), pp. 3735-3738. 